\title{
Assessing blight and its economic impacts: a case study of Dallas, $T X$
}

\author{
P. Maghelal, S. Andrew, S. Arlikatti \& H. S. Jang \\ Department of Public Administration, University of North Texas, USA
}

\begin{abstract}
While much has been written about sustainable cities, few have explored the concept of "blight" in the context of community viability. As indicators of blight, studies have often examined the presence of vacant lots attracting crime, dumping, abandoned or dilapidated housing and commercial and rental properties owned by non-complying absentee landlords. However, the quantitative estimates focusing on the physical attributes of a community are limited by incomplete data collected at one point in time or one neighborhood. The objective of this paper is to examine key indicators of urban blight that influences the sustainability and long term viability of neighborhoods and communities. This research also provides novel ways to measure the consequences of blighted areas in terms of physical, economic, and sociodemographic over time. Geographic Information Systems (GIS) is used to create blight variable layers and then aggregated to identify the degree of blight in the City of Dallas. The analysis captures the magnitude of blight thus allowing for meaningful comparisons and systematically evaluating the virtual effects of blight. We found blight conditions generally clustered in four parts of the city highlighting the importance of monitoring and code enforcement activities. Using publicly available data, we assess the economic burden these blighted communities impose on the city and make recommendations to mitigate such impacts in future for the sustainable growth of the city.

Keywords: urban blight, sustainable cities, index, economic impact, cost analysis, City of Dallas.
\end{abstract}

\section{Introduction}

Numerous studies have described "urban blight" as a multidimensional concept and agree that collectively these dimensions have an adverse effect on 
surrounding neighborhoods. Wilson and Kelling's [1] notion of a "broken window syndrome" suggests that urban blight can be captured through the severity of untended properties and abandoned structures, reflecting the breakdown of physical, social, and economic conditions of a neighborhood. These conditions also signal lax code enforcement and control mechanisms that ensure proper maintenance by property owners. Blight has been defined in terms of support or lack of resource allocation (i.e., the willingness of local residents and public institutes to safeguard the general welfare of others), as well as a reflection of police power that a city commands to coerce property owners to repair and invest in the upkeep of physical structures through special building codes and municipal zoning codes [2].

Quantification of blight has changed and improved significantly over year. The progressive era defined it in terms of poor structural housing, while midtwentieth century included the effects such as depreciation of property value and decline in demand for services in understanding the concept of blight. The latter part of the twentieth century conceptualized blight as those with a high incidence of urban poverty, slums, and ghettos located in inner cities with old, substandard overcrowded housing, high crime rates, high concentration and proportion of blacks and other minority households. Recent studies have operationalized the concept of urban blight in terms of neighborhood attributes including crime, heavy traffic, and environmental degradation, and employed survey instruments as a way to subjectively assess blight [3].

Major scholarly work related to the conceptual definition of blight suggests that research has moved from objective measures such as the structural aspects of condemned housing, to a more process driven subjective assessment of understanding of what leads to blight by examining neighborhood quality and socio-economic characteristics of neighborhood residents. Most empirical studies have used secondary data sources such as Census data, Local Housing Survey Data, AHS datasets and Realtor databases and combined physical and socio-economic indicators to study blight.

We argue that blight neighborhoods differ only in degrees to non-blighted areas. As indicators of blight, studies have often examined the presence of vacant lots attracting crime, dumping, abandoned or dilapidated housing and commercial and rental properties owned by non-complying absentee landlords. However, the quantitative estimates focusing on the physical attributes of a community are limited by incomplete data collected at one point in time or one neighborhood. The objective of this paper is to examine key indicators of urban blight that influences the sustainability and long term viability of neighborhoods and communities.

\section{Assessment of blight}

\subsection{Study area}

Dallas is currently the third largest city in the state of Texas with a population of approximately 1.2 million [4]. It encompasses a land area of 384.93 square 
miles and is the ninth-largest city in the US and part of the fourth-largest metropolitan area in the nation. Parts of the city of Dallas lie within five counties namely: Dallas, Denton, Collin, Kaufman and Rockwall. The census tracts that overlap the boundaries of the City of Dallas are located in these five counties. In all, 383 census tracts overlap with the city of Dallas. For the purpose of consistency and ease of data collection and management, this study investigated the conditions of blight for the tracts that overlap with the city limits only in the Dallas County. This resulted in a total of 350 tracts being investigated (see Figure 1).

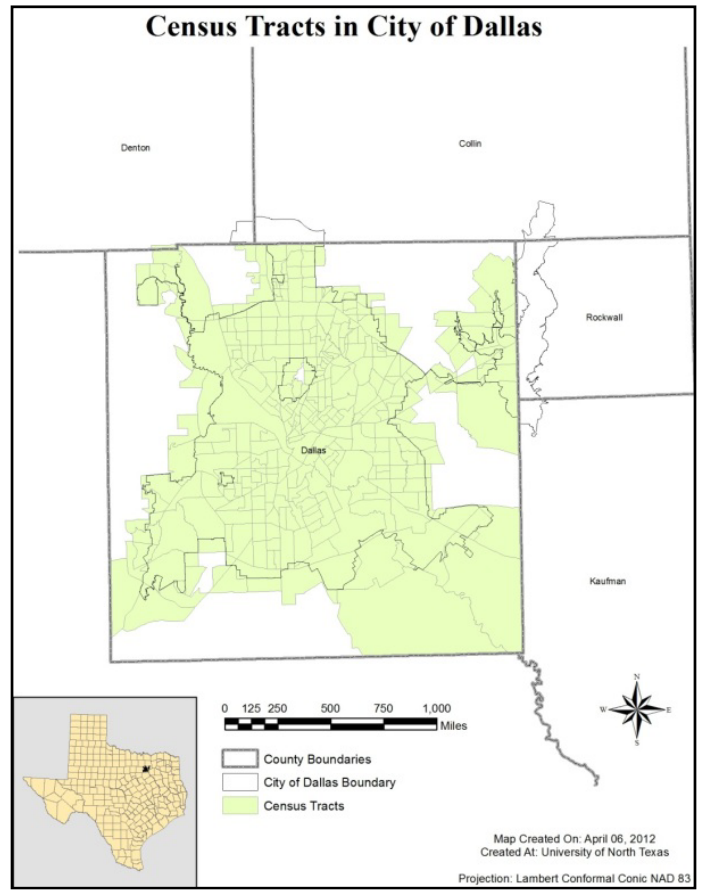

Figure 1: Census tracts selected for the study.

\subsection{Creation of Blight Index}

The operational definition of blight provided by Dallas Area Habitat for Humanity was strictly adhered to and guided the creation of the Composite Blight Index to include physical quality of life indicators as well as socioeconomic indicators. This definition emphasizes that, "Neighborhood blight consists of those conditions that threaten the health and safety of neighborhood residents, depress an area's quality of life and jeopardize the social and economic viability of an area." 


\subsubsection{Physical indicators}

Based on our literature review and the availability of data for the City of Dallas, a strategic selection of seven physical indicators characterizing blight was made. Although not meant to be comprehensive they are realistic given the nature of housing stock, changing demographics, migration, loss in economic base, and other challenges faced by the City of Dallas. The data for analyses were gathered from online public sources, including publically available databases and news reports, as well as face-to-face conversations with key personnel from various departments including the Department of Code Compliance, County Tax Assessors office (properties with outstanding tax liens), Dallas Police Department (violent and nonviolent crimes), and Dallas Housing Acquisition and Development Corporation (DHADC) at Dallas City Hall, Dallas Landbank and the Real Estate Management Department, and most importantly, obtained through numerous Open Record requests. These were merged at the Census Block/Tract level along with the Census 2010 data. The physical indicators were aggregated (count) for each census tract in the City of Dallas and mapped to create a "Physical Index" (see Fig. 2(a)).

The seven physical indicators selected and mapped were:

1. Abandoned;

2. Vacant residential;

3. Vacant commercial;

4. Mortgage foreclosed;

5. Tax foreclosed property;

6. Tax delinquent;

7. Demolished.

\subsubsection{Socio-economic indicators}

Rosenbaum et al. [5] suggest that one's opportunity to reside in "neighborhoods possessing high-quality resources is differentially distributed across such characteristics as race and immigration status..." (pg. 626). Studies on the locational attainment process have used Census derived tract characteristics such as the proportion of whites, median household income and other quality of life indicators such as the risk of crime [6].

Thus based on the review of literature and socio-economic blight measures used by other US cities, a selection of seven relevant socio-economic indicators was made to capture household attainment levels. The socio-economic indicators were downloaded from the US Census Bureau 2010 and mapped to create a "Socio-economic Index" (see Fig. 2(b)).

The seven socio-economic measures selected were:

1. Poverty;

2. Unemployment;

3. Ethnicity;

4. Race;

5. Renter household;

6. Population;

7. Single parent household. 
Table 1: $\quad$ List of indicators selected for Composite Blight Index for Dallas.

\begin{tabular}{|c|c|c|c|}
\hline & Physical indicators & Census tract measures & Source \\
\hline 1 & Abandoned & Mail undeliverable for over 90 days & USPS \\
\hline 2 & Vacant residential & Number of vacant residential plots & DCAD \\
\hline 3 & Vacant commercial & Number of vacant commercial plots & DCAD \\
\hline 4 & Mortgage foreclosed & $\begin{array}{l}\text { Number of mortgage foreclosed } \\
\text { properties }\end{array}$ & County Tax Off.* \\
\hline 5 & Tax foreclosed & Number of tax foreclosed properties & Land Bank \\
\hline 7 & Tax Delinquent & Number of tax delinquent properties & County Tax Off.* \\
\hline \multirow[t]{2}{*}{8} & Demolished & Number of demolished properties & Dallas City Hall \\
\hline & \multicolumn{3}{|c|}{ Social-economic indicators } \\
\hline 8 & Poverty & Rate of poverty & US Census 2010 \\
\hline 9 & Unemployment & Unemployment rate & US Census 2010 \\
\hline 10 & Ethnicity & Number of Hispanic individuals & US Census 2010 \\
\hline 11 & Race & Number of nonwhite individuals & US Census 2010 \\
\hline 12 & Renter occupied & Number of renter households & US Census 2010 \\
\hline 13 & Population & Population density 2010 & US Census 2010 \\
\hline 14 & $\begin{array}{l}\text { Single parent } \\
\text { household }\end{array}$ & Number of single parent households & US Census 2010 \\
\hline
\end{tabular}

Notes: USPS - United States Postal Service; DCAD - Dallas County Appraisal District; *Dallas County Tax Office Realtor Database.

\subsubsection{Composite Blight Index}

To better illustrate this selection for classifying and comparing the conditions of blighted neighborhoods at the Census tract level across the City, a Composite Blight Index Map was created using the seven selected physical indicators and seven selected socio-economic indicators. Finally, the decision to capture the overall measure of blight in neighborhoods was made by assigning all 14 measures (Table 1) equal "Weights," so that the total added up to a 100 (see Fig. 3).

The frequency distribution of the blight index by census tracts for physical indicators, socio-economic indicators, and the combined composite index is presented in Table 2. Based on the analysis, 48 census tracts in the City of Dallas are classified as "Blighted." This index will be useful in focusing blight reduction strategies in select neighborhoods within these census tracts and monitor the positive changes over time. 


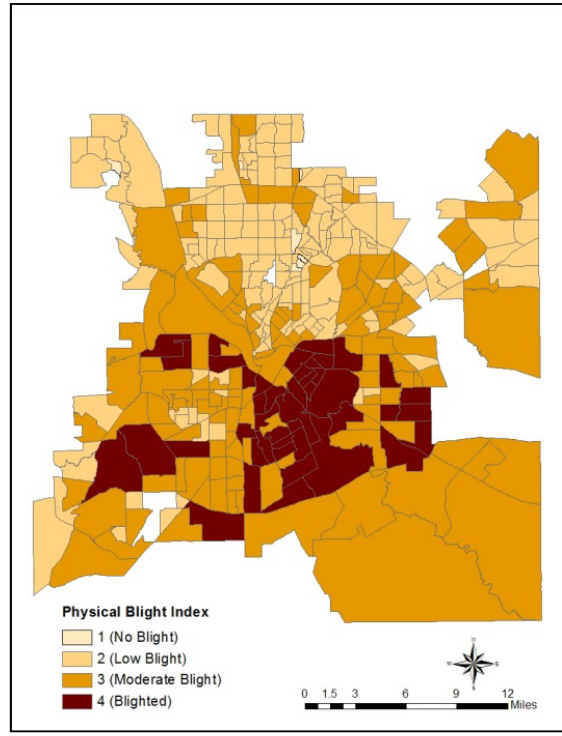

(a)

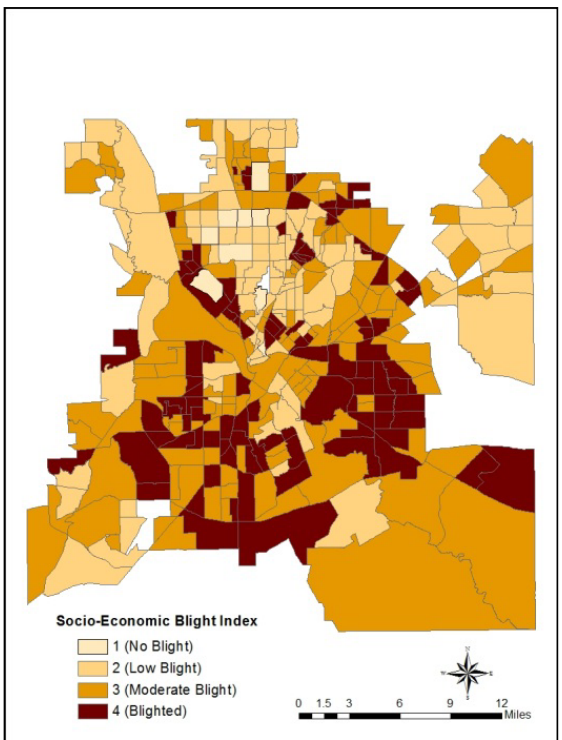

(b)

Figure 2: Physical (a) and Socio-Economic (b) Blight Index for the City of Dallas.

Table 2: Number of Census tracts in the three blight categories.

\begin{tabular}{|c|c|c|c|c|}
\hline & Categories & Physical indicators & $\begin{array}{l}\text { Socio-economic } \\
\text { indicators }\end{array}$ & Composite Index \\
\hline 1 & No blight & 7 & 9 & 0 \\
\hline 2 & Low blight & 172 & 102 & 118 \\
\hline 3 & Moderate blight & 127 & 134 & 184 \\
\hline 4 & Blighted & 44 & 105 & 48 \\
\hline & Total & 350 & 350 & 350 \\
\hline
\end{tabular}

Note: the frequency table illustrates that none of the 350 Census tracts constituting the City of Dallas is free of blight suggesting that urban blight is a matter of degree.

\subsection{Economic impact of blight to the City of Dallas}

We examined the potential cost of blight to the City of Dallas through property tax delinquencies and non-tax labor liens. Specifically, the cost of blight is operationalized by examining the amount of delinquent property taxes and nontax liens based on the blight categories. 


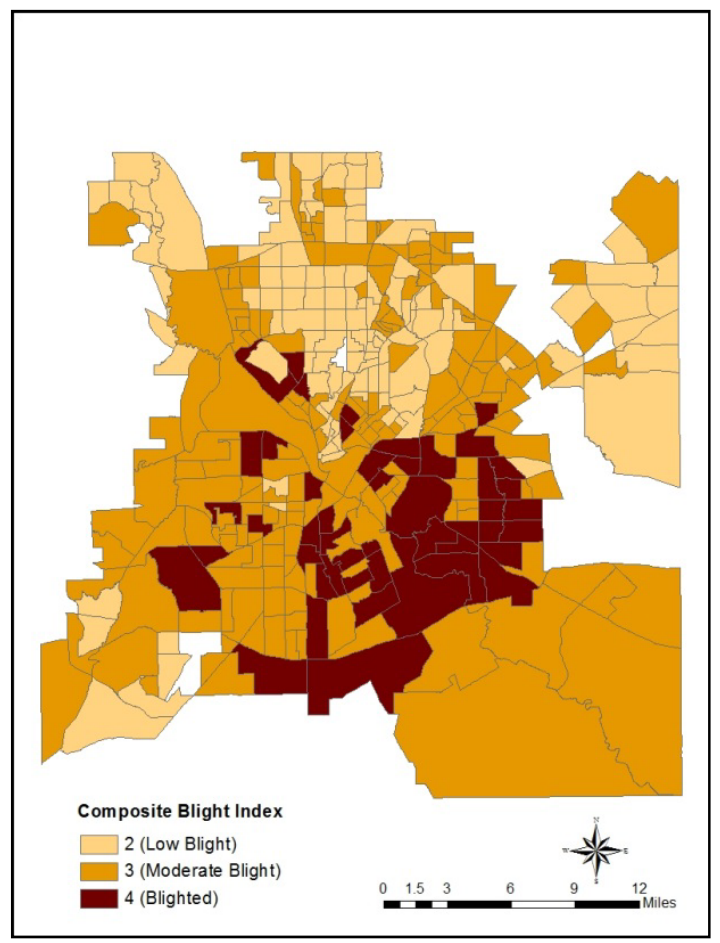

Figure 3: Composite Blight Index.

\subsubsection{Delinquent property taxes}

The data on the total amount of delinquent property taxes was provided by the Dallas County Tax Office, IT Department, which contained the sum of levy balance between 1976 and 2011 at the individual property level (Table 3). The non-tax lien data, which was also at the individual property level, was provided by Dallas City Hall.

The pattern of distribution for properties delinquent in paying taxes, by blight categories suggests that these are once again found mainly in the moderate blight and high blight areas with $49.4 \%$ individual properties in moderate blight areas, and $40.8 \%$ found in high blight areas.

\subsubsection{Non-tax liens}

The added cost of blight to the city of Dallas can also be determined by the amount of outstanding principal and interest owed to the city through non-tax liens for each year (not reflecting the cumulative amount from previous years). Based on the data provided by Dallas City Hall, the total outstanding amounts were \$2.53 million in 2010, \$3.08 million in 2011, and \$3.14 million in 2012 (Table 4). 
Table 3: Delinquent property taxes/vacant residential and non-tax liens by blight categories.

\begin{tabular}{lccc}
\hline & \multicolumn{3}{c}{ Blight categories } \\
\cline { 2 - 4 } & Low & Moderate & High \\
\hline Properties with delinquent property taxes & $9.8 \%$ & $49.4 \%$ & $40.8 \%$ \\
Vacant residential properties & $3.6 \%$ & $50.0 \%$ & $46.5 \%$ \\
Non-Tax (labor) Liens (2011) & $0.3 \%$ & $44.6 \%$ & $55.1 \%$ \\
\hline
\end{tabular}

Table 4: Non-tax lien dues.

\begin{tabular}{ccccc}
\hline & \multicolumn{3}{c}{ Non-tax liens (principal and interest) } & \\
\cline { 2 - 4 } & $\begin{array}{c}\text { No. of } \\
\text { parcels }\end{array}$ & Original amount & $\begin{array}{c}\text { Outstanding } \\
\text { amount }\end{array}$ & \% Outstanding \\
\hline 2010 & 4,831 & $\$ 2,877,577.82$ & $\$ 2,537,709.99$ & $88 \%$ \\
2011 & 5,992 & $\$ 3,811,521.21$ & $\$ 3,086,490.27$ & $81 \%$ \\
2012 & 6,604 & $\$ 3,578,873.68$ & $\$ 3,140,835.62$ & $88 \%$ \\
\hline
\end{tabular}

\subsubsection{Code enforcement}

The operational cost of $\$ 15,515,364$ for providing Neighborhood Code Compliance services was used against the total number of citations $(8,573)$ issued in 2011 to arrive at an average cost of $\$ 1,809.79$ per code violation. This was used to project the cost of code enforcement in each blight category (see Table 5). It is clear that code enforcement costs due to civil code violations quickly add up in moderate to approximately $\$ 5.8$ million and $\$ 4.3$ million in high blight categories. Although the numbers of criminal code citations are only $29 \%$ of the total number of citations, most of these are in the moderate and high blight categories as well. The total projected cost for code enforcement in moderate blight areas is approximately $\$ 8.4$ million and in blighted Census Tracts is $\$ 6.1$ million.

\subsubsection{Violent and non-violent crimes}

The operational budget of $\$ 297,026,247$ for providing "Crime Prevention and Management" was used against the total number of violations (i.e., 70,123) issued in 2011 to arrive at an average cost of $\$ 4235.79$ per code violation. This was used to project the cost of crime reduction in each blight category (see Table 6). Surprisingly, the cost of combating non-violent crimes in the moderate blight category really stands out at approximately $\$ 198$ million, while it is $\$ 81$ million in the high blight category. 
Table 5: Projected cost of code enforcement in blight categories.

\begin{tabular}{lrrr}
\hline Type of citation & Low & Moderate & High \\
\hline Civil & $\$ 711,251.40$ & $\$ 5,838,414.80$ & $\$ 4,354,378.80$ \\
Criminal & $\$ 179,170.20$ & $\$ 2,544,578.80$ & $\$ 1,780,843.20$ \\
\hline Total & $\$ 890,421.60$ & $\$ 8,382,993.60$ & $\$ 6,135,222.00$ \\
\hline
\end{tabular}

Table 6: Total cost of crime reduction in blight categories.

\begin{tabular}{lcrc}
\hline \multicolumn{1}{c}{ Type of crime } & Low & \multicolumn{1}{c}{ Moderate } & \multicolumn{1}{c}{ High } \\
\hline Violent crimes & $\$ 3,113,304.92$ & $\$ 20,937,505.03$ & $\$ 10,470,870.41$ \\
Non-violent crimes & $\$ 45,166,218.11$ & $\$ 198,492,934.20$ & $\$ 81,478,419.00$ \\
\hline Total & $\$ 48,279,523.02$ & $\$ 219,430,439.23$ & $\$ 91,949,289.41$ \\
\hline
\end{tabular}

\subsubsection{Demolition cost}

There was no demolition costs associated with properties in low blight areas. However, demolition costs for commercial properties in the "moderate blight" category totaled $\$ 1,431,741.50$ approximately $83 \%$, while the total cost of demolition in the 'high blight' category totaled \$277,368, which is approximately $16 \%$ of the total cost (Table 7). It is important to note that demolition cost for the moderate properties is more than high blight areas. This could be indicative of the City being proactive in dealing with locations that are moderately blight or on the contrary with the limited availability of human and financial resources, they focus on dealing with moderately blighted areas rather than the highly blighted areas.

Table 7: Maximum demolition costs (estimated) based on CDU rating, for Composite Blight Index categories.

\begin{tabular}{lrrr}
\hline CDU classification & Moderate blight & High blight & \multicolumn{1}{c}{ Total } \\
\hline Good & $7,280.00$ & & $7,280.00$ \\
Average & $\$ 1,120,126.00$ & $\$ 166,614.00$ & $\$ 1,286,740.00$ \\
Poor & $304,335.50$ & $110,754.00$ & $415,089.50$ \\
\hline Total $(\$)$ & $\$ 1,431,741.50$ & $\$ 277,368.00$ & $\$ 1,709,109.50$ \\
\hline
\end{tabular}




\section{Results}

This study seeks to inform the stakeholders of Dallas' forgotten neighborhoods and to better present its neighborhood revitalization goals. Through this research we created a composite blight index for the city of Dallas that the city officials, nonprofit agencies and policy makers can use to observe the patterns of blight and target intervention appropriately. We describe the problem of blight in Dallas' neighborhoods, evaluate the size of the blight problem and identify the neighborhoods hardest hit by blight. Finally, detailed public and private costs of neighborhood blight are presented.

\subsection{Cost of unpaid labor liens}

The financial implications of unpaid labor liens demonstrated that these were likely to be in "high blight" areas. These under-maintained properties overgrown with weeds and noncompliant with city codes create unsafe conditions and negative externalities for the communities in which they are located. Our findings for the City of Dallas suggest a need to identify properties to determine if they can assist the owners, especially owners of low-value properties. Failing to do this portends that the property will enter tax foreclosure status. Such actions may help mitigate the loss that the City bears through lost taxes and abandonment.

\subsection{Cost to city of tax-delinquent properties}

Tax-delinquent properties that are ultimately not redeemed from tax foreclosure by owners or mortgage holders and appear as a list of "surplus properties" that cannot be auctioned off, are the most costly to cities and require immediate attention. Numerous attempts were made to no avail, to obtain this list of surplus properties that the Dallas County Sheriff's office distributes to the City of Dallas Real Estate Division and this department tries to auction. This list is critical for calculating the cost the City continues to pay, to maintain them and to keep them code compliant. Future research should focus on these properties and identify those that can be demolished or alternative actions taken.

\subsection{Approaches in neighborhood revitalization efforts}

A brief review of public and nonprofit programs and strategies that have worked successfully to address the multi-dimensional nature of blight suggests there is no one perfect way of addressing this problem and different approaches should be carefully assessed and modified based on their relevance and applicability to the City of Dallas. Non-profit sector programs such as Community Housing Development Organizations (CHDO) program; Habitat for Humanity; and Builder for Hope CDC as well as public programs such as the Mortgage Assistant Program (MAP); People Helping People (PHP) Program; and Major Systems Repair Program (MSRP) can be utilized as strategies and approaches to deal with blight. 


\section{Conclusion}

This study assessed the blight in the City of Dallas by spatial mapping and aggregation of physical and socio-economic indicators of blight. The economic impact of such blighted neighborhood on the city of Dallas indicates the financial burden these communities impose on the cities and the need to adapt effective measures to monitor and mitigate the effect of blight. However, this requires further analysis of policies and approaches at the local level. Also, this study used publicly available data for the evaluation of blight. Although this allows for other similar and comparable studies across the nation, the nonavailability of privately generated and stored data such as property sale values can enhance the implication of such studies.

The intended purpose of this study is thus twofold. First, it will allow public, private and non-profit agencies to use the findings to inform its advocacy for Dallas's forgotten neighborhoods and revitalize such neighborhoods. Second, the estimated economic cost of blight to the City of Dallas will hopefully spark public discourse to help target interventions that are aimed at recouping delinquent property taxes and unpaid liens. These findings offer alternatives to stem the astronomical costs that the City bears to demolish vacant and unsightly structures.

\section{References}

[1] Wilson, J.Q. and Kelling, G.L. (1982). Broken Window accessed at http://www.manhattan-institute.org/pdf/_atlantic_monthly-broken_windows .pdf on September 17, 2012.

[2] Gordon, C. (2003). Blighting the Way: Urban Renewal, Economic Development, and the Elusive Definition of Blight. Fordham Urb. LJ, 31, 305.

[3] Greenberg, M. and Crossney, K. (2007). Perceived Neighborhood Quality in the United States: Measuring Outdoor, Housing and Jurisdictional Influences. Socio-Economic Planning Sciences, 41(3): 181-194.

[4] United States Census (US Census 2010) accessed at http://www.census.gov/

[5] Rosenbaum, E., Friedman, S., Schill, M.H. and Buddelmeyer, H. (1999). Nativity Differences in Neighborhood Quality Among New York City Households. Housing Policy Debate, 10(3): 625-658.

[6] Alba, R.D. Logan, J.R. and Bellair, P.L. (1994). Living With Crime: The Implications of Racial/ Ethnic Differences in Suburban Location. Social Forces, 73(2): 395-434. 